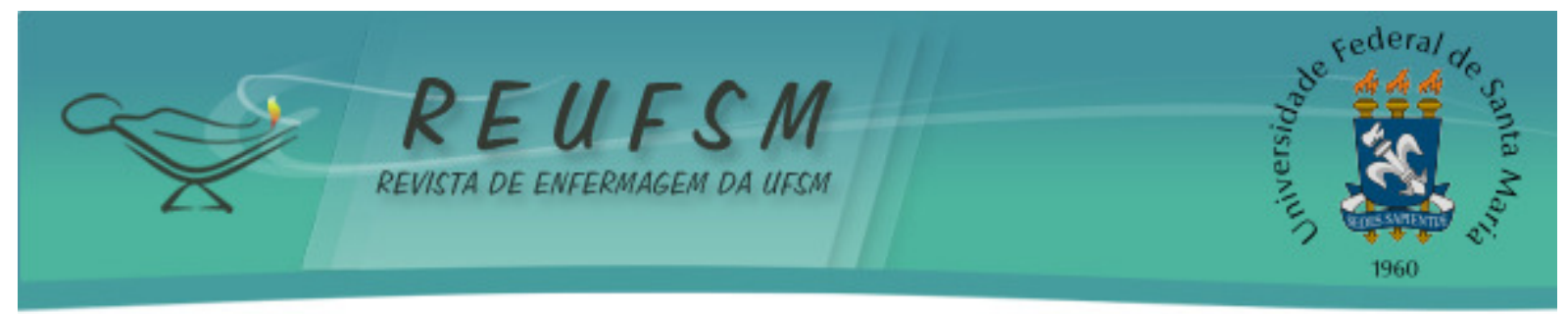

ARTIGO ORIGINAL

\title{
PROMOÇÃO DO ALEITAMENTO MATERNO NOS BANCOS DE LEITE HUMANO DO ESTADO DO RIO DE JANEIRO
}

\section{PROMOTION OF BREASFEEDING ON HUMAN MILK BANKS OF RIO DE JANEIRO \\ LA LACTANCIA MATERNA EN LOS BANCOS DE LECHE HUMANA DEL ESTADO DE RIO DE JANEIRO}

Doi: $10.5902 / 2179769216498$

\author{
Maria Bertilla Lutterbach Riker Branco ${ }^{1}$ \\ Valdecyr Herdy Alves ${ }^{2}$ \\ Diego Pereira Rodrigues ${ }^{3}$ \\ Rosangela de Mattos Pereira de Souza ${ }^{4}$ \\ Amanda Fernandes do Nascimento da $\mathrm{Cruz}^{5}$ \\ Tuâny Figueiredo Marinho ${ }^{6}$
}

RESUMO: Objetivo: descrever a prática assistencial dos profissionais de saúde na promoção do aleitamento materno nos Bancos de Leite Humano do Estado do Rio de Janeiro. Método: estudo descritivo, exploratório, qualitativo, realizado em cinco Bancos de Leite Humano, com participação de vinte e cinco profissionais de saúde atuantes nesses serviços. Os dados foram coletados por intermédio de entrevista semiestruturada e posteriormente submetidas à análise de conteúdo na modalidade temática. Resultados: foram obtidas três categorias: "A orientação no trabalho do Banco de Leite Humano: um espaço real da promoção do aleitamento materno", "O Banco de Leite Humano como promotor do aleitamento materno no espaço familiar" e "A mídia como ferramenta de promoção do aleitamento materno no espaço do Banco de Leite Humano". Conclusão: a promoção do aleitamento materno nos Bancos de Leite Humano é realizada pelos profissionais de saúde com parceria da mídia e da família, elementos importantes para seu sucesso.

Descritores: Bancos de leite; Pessoal de saúde; Aleitamento materno.

ABSTRACT: Aim: to describe the care practice of health professionals to support breastfeeding in Human Milk Banks of Rio de Janeiro. Method: descriptive, exploratory and qualitative study in five Human Milk Banks, with participation of twenty five health professionals working on health care services. The data were collected through semistructured interviews and submitted to content analysis in the thematic mode. Results: three categories were found: "An orientation to the work at a Human Milk Bank: a space to conduct suitably breastfeeding", "The use of the Human Milk Bank to promote the breastfeeding at home" and "The media as a promotional tool of breastfeeding within the

\footnotetext{
${ }^{1}$ Enfermeira, Mestre em Saúde Materno Infantil, Hospital Universitário Antônio Pedro, Niterói, Rio de Janeiro, Brasil. E-mail: bertillariker@yahoo.com.br

${ }^{2}$ Enfermeiro, Doutor em Enfermagem, Escola de Enfermagem Anna Nery, Universidade Federal do Rio de Janeiro, Rio de Janeiro, Brasil. Professor Titular do Departamento Materno-Infantil e Psiquiatria, Escola de Enfermagem Aurora de Afonso Costa, Universidade Federal Fluminense, Niterói, Rio de Janeiro, Brasil. E-mail: herdyalves@yahoo.com.br

${ }^{3}$ Enfermeiro, Mestre em Enfermagem, Escola de Enfermagem Aurora de Afonso Costa, Universidade Federal Fluminense, Niterói, Rio de Janeiro, Brasil. E-mail: diego.pereira.rodrigues@gmail.com

${ }^{4}$ Enfermeira, Mestre em Saúde Materno Infantil, Hospital Universitário Antônio Pedro, Niterói, Rio de Janeiro, Brasil. E-mail: rosangelademattos@yahoo.com.br

${ }^{5}$ Enfermeira, Mestranda em Ciências do Cuidado em Saúde, Escola de Enfermagem Aurora de Afonso Costa, Universidade Federal Fluminense, Niterói, Rio de Janeiro, Brasil. E-mail: amandafernandesnc@gmail.com

${ }^{6}$ Enfermeira, graduada, Escola de Enfermagem Aurora de Afonso Costa, Universidade Federal Fluminense, Niterói, Rio de Janeiro, Brasil. E-mail: tuany.f.marinho@gmail.com
} 


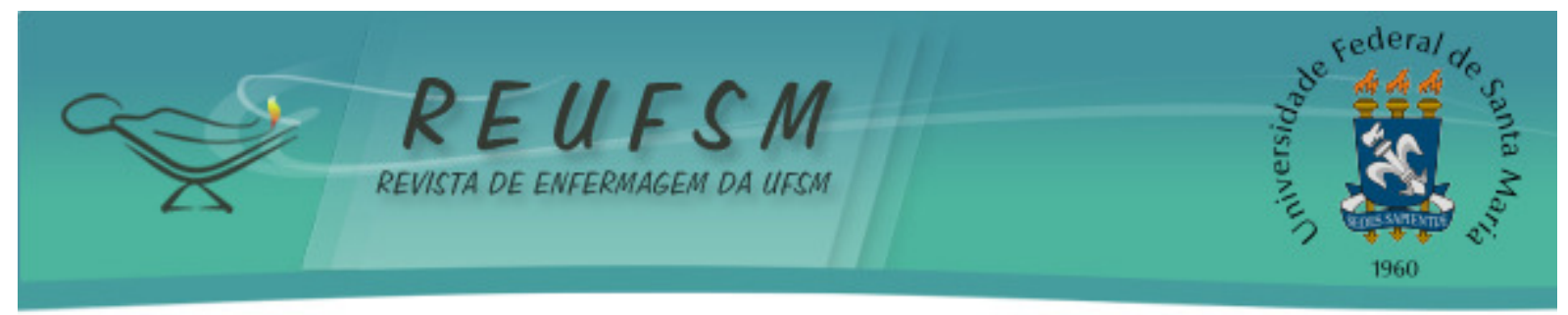

Human Milk Bank". Conclusion: the promotion of breastfeeding in Human Milk Banks is performed by health care professionals working in partnership with the media and the family, essential elements for its success.

Descriptors: Milk banks; Health personnel; Breast feeding.

RESUMEN: Objetivo: describir la práctica asistencial de los profesionales de la salud en la promoción de la lactancia materna en Bancos de Leche Humana del Estado de Rio de Janeiro. Método: Estudio cualitativo-descriptivo y exploratorio, realizado en cinco bancos de leche humana, en que participaron veinticinco profesionales de la salud que trabajan en estos servicios. Los datos fueron recolectados en entrevistas semi-estructuradas y sometidos al análisis de contenido en la modalidad temática. Resultados: se obtuvieron tres categorías: "La orientación de la lactancia materna sobre la labor del Banco de Leche Humana ", " La familia y el banco de leche humana " y "Los medios de comunicación de promoción de la lactancia materna". Conclusión: la promoción de la lactancia materna en los bancos de leche humana es realizado por profesionales de la salud con asociación con los medios de comunicación y la familia, elementos importantes para su éxito.

Descriptores: Bancos de Leche; Personal de salud; Lactancia materna.

\section{INTRODUÇÃO}

Os movimentos sociais e governamentais realizados nas últimas décadas em prol do aleitamento materno vêm transformando a prática assistencial dos profissionais de saúde que atuam na área da saúde da mulher e da criança, em especial nos Bancos de Leite Humano (BLH). Estes espaços são considerados a Casa da Amamentação e visam à segurança nutricional das crianças. Para isso, a promoção do aleitamento materno é uma das Políticas de Saúde implementadas pelos profissionais que neles atuam. ${ }^{1}$

A promoção em saúde no campo do aleitamento materno percorre os espaços da Sala de Parto, Alojamento Conjunto (AC) e Unidade Básica de Saúde (UBS), articulando-se com a Iniciativa Hospital Amigo da Criança (IHAC) e a Iniciativa Unidade Básica Amiga da Amamentação (IUBAAM), ações que favorecem o aumento das taxas de aleitamento materno exclusivo e a melhoria da qualidade de vida de muitas crianças. ${ }^{2}$

A prevalência do aleitamento materno exclusivo até os seis primeiros meses no ano de 2010 foi de 40,7\% na cidade do Rio de Janeiro. Este índice condizia com a intensificação das ações de promoção do aleitamento materno no Brasil $^{3-4}$, tanto assim que, em 2012, no Estado do Rio de Janeiro haviam 17 BLH e 5 Postos de Coleta de Leite Humano (PCLH), totalizando 102.595 atendimentos em seus espaços institucionais. ${ }^{3-4}$

Destacava-se a ampliação, no país, do quantitativo de BLH responsáveis pela promoção, proteção e apoio ao aleitamento materno, e também pela execução de atividades de coleta, processamento e controle de qualidade do colostro, leite de transição e leite humano para posterior distribuição a uma população vulnerável que deles dependiam como fatores de sobrevivência. Esses avanços tem sido de extrema importância para que o Brasil alcance a meta de diminuição das taxas de mortalidade infantil.'

As ações dos BLH têm como proposta a promoção da amamentação, a manutenção da lactação e a doação de leite humano, e como intuito, garantir a segurança alimentar para prematuros e recém-nascidos. Para tal, perpassa pela difusão da educação em saúde para mulheres nutrizes, famílias e população, objetivando trabalhar a segurança alimentar infantil e garantindo o cumprimento da recomendação da Organização Mundial da Saúde em relação ao aleitamento materno como primeira opção alimentar exclusiva para todos os lactentes, até os seis meses de vida. ${ }^{4-5}$ 


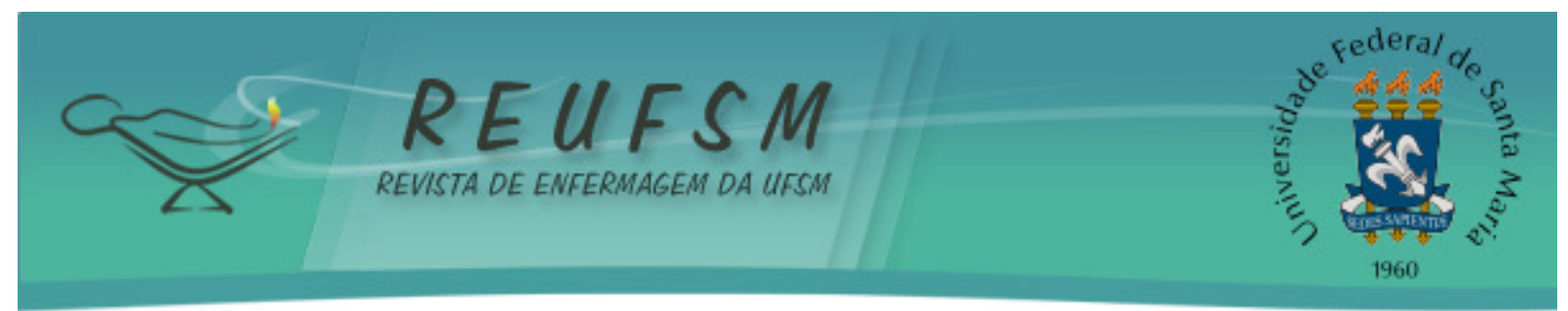

Para a realização das ações de promoção do aleitamento materno nos espaços dos BLH, são necessários conhecimentos específicos como saúde da mulher e da criança, além de habilidades no manejo das diversas fases da lactação. ${ }^{4}$ Sendo assim, as equipes de saúde dos BLH e dos PCLH são consideradas promotoras da amamentação. Indaga-se, portanto: como se dá esse fazer pelos profissionais de saúde que atuam nos BLH norteados pela política de promoção ao aleitamento materno?

Diante do exposto, determinou-se como objetivo: descrever a prática assistencial dos profissionais de saúde na promoção do aleitamento materno nos Bancos de Leite Humano do Estado do Rio de Janeiro.

\section{MÉTODO}

Estudo descritivo, exploratório, com abordagem qualitativa, realizado em cinco Bancos de Leite Humano do Estado do Rio de Janeiro.

A pesquisa foi aprovada pelo Comitê de Ética em Pesquisa da Faculdade de Medicina do Hospital Universitário Antônio Pedro, da Universidade Federal Fluminense, sob Protocolo $n^{\circ}$ 191-11, atendendo a Resolução n 196/96 do Conselho Nacional de Saúde.

No período da seleção haviam $17 \mathrm{BLH}$ distribuídos em cinco mesorregiões: Baixadas Litorâneas, Centro Fluminense, Metropolitana do Rio de Janeiro, Noroeste Fluminense e Norte Fluminense, das quais duas apresentavam o maior número de BLH; nas demais, havia um BLH por mesorregião. Neste caso, optou-se por um banco de leite de cada mesorregião, e onde havia mais de um, foi realizado sorteio aleatório simples, resultando em um total de cinco campos da pesquisa, a saber: 1) BLH do Hospital Universitário Antônio Pedro; 2) BLH do Hospital Maternidade Nova Friburgo; 3) BLH do Hospital dos Plantadores de Cana; 4) BLH do Hospital São João Batista; 5) BLH Nutricionista Gilsara do Bonfim Santos.

Participaram do estudo vinte e cinco (25) profissionais de saúde que atenderam aos seguintes critérios de inclusão: 1) serem profissionais da área da saúde com pelo menos quatro meses de efetiva atuação no BLH; 2) terem realizado um dos cursos de manejo clínico para o aleitamento materno (Iniciativa Hospital Amigo da Criança ou Iniciativa Unidade Básica Amiga da Amamentação); e por exigência da Agência Nacional de Vigilância Sanitária (ANVISA), também o Curso de Controle de Qualidade e Processamento do Leite Humano, em que os profissionais adquirem conhecimento de todo o processamento do leite humano dentro do BLH até a sua distribuição. Os profissionais de saúde em licença médica, gozo de férias ou outro impedimento no período previsto para a coleta de dados, foram excluídos do estudo.

Todos os participantes assinaram o Termo de Consentimento Livre e Esclarecido condicionando a sua participação voluntária, sendo-lhes assegurado o anonimato e o sigilo das informações com a utilização de um código alfanumérico significando: P-profissional; S-saúde, seguido de um ordinal, conforme a realização das entrevistas $\left(\mathrm{PS}_{1}, \ldots, \mathrm{PS}_{25}\right)$.

Os dados foram coletados por meio de entrevista individual, semiestruturada, com perguntas abertas e fechadas ${ }^{6}$. A coleta das informações deu-se durante os meses de julho de 2012 à fevereiro de 2013, nos cinco BLH referidos. As entrevistas foram gravadas digitalmente com autorização prévia dos participantes; depois foram transcritas na íntegra pelo próprio pesquisador. Os textos foram submetidos à leitura minuciosa visando facilitar a compreensão e a interpretação dos dados que, em seguida, foram qualitativamente processados com base na análise de conteúdo, na modalidade temática ${ }^{7}$ em suas diversas fases: pré-análise; exploração do material; tratamento dos resultados, inferência e interpretação ${ }^{7}$, resultando nas seguintes categorias temáticas: A orientação no trabalho do Banco de Leite Humano: um espaço real da promoção do aleitamento materno; O Banco de 


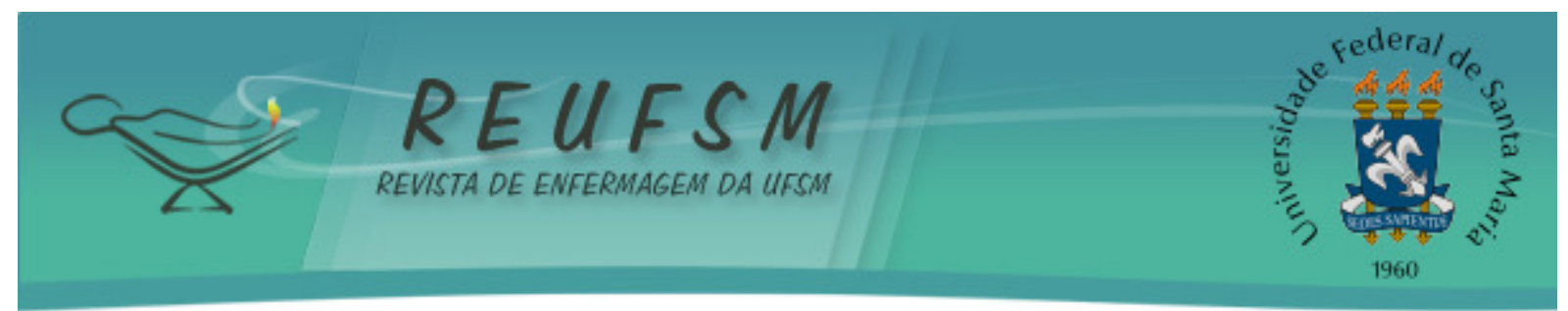

Leite Humano como promotor do aleitamento materno no espaço familiar e A mídia como ferramenta de promoção do aleitamento materno no Banco de Leite Humano.

\section{RESULTADOS E DISCUSSÃO}

\section{A orientação no trabalho do Banco de Leite Humano: um espaço real da promoção do aleitamento materno}

As orientações para o aleitamento materno realizadas pelos profissionais de saúde dos BLH compreendem as ações que geram mais segurança para a mulher/nutriz, a família e toda comunidade envolvida nessa prática. No Alojamento Conjunto as informações sobre os benefícios do aleitamento materno, pautando a segurança alimentar, são fortalecidas quando ocorre o debate com as mulheres acerca do tema. Abrangem também os cuidados básicos da mulher e do seu bebê para a manutenção da lactação evitando, assim, possíveis transtornos e indicando caminhos para o sucesso da amamentação como parte do trabalho dos BLH. Os depoimentos dos profissionais de saúde expressam como são realizadas as orientações sobre o aleitamento materno junto às mulheres/nutrizes assistidas no BLH:

a gente assiste também as mulheres internadas [...] faz uma fala coletiva sobre a importância e benefícios do leite materno para o filho dela e sobre as necessidades delas [...] elas podem procurar o BLH em caso de alguma intercorrência. [...] orientamos como ela faz o aleitamento materno, a gente fala com todas elas sobre a pega e a posição. (PS1)

a principal orientação aqui do nosso Banco é primeiro a promoção, o incentivo ao aleitamento materno, posteriormente a gente capta as doações. (PS4)

A prática da orientação no campo da promoção ao aleitamento materno perpassa pelo aconselhamento, que inclui habilidades como ouvir atentamente, transmitir confiança e apoio às mães que pretendem amamentar e/ou estão amamentando, sempre articuladas com as técnicas de comunicação. As orientações realizadas pelos profissionais de saúde do BLH possibilitam uma escuta sensível, contribuindo para que a mulher-nutriz possa se planejar, tomar decisões e fortalecer sua autoconfiança e autoestima para lidar com as dificuldades do processo de amamentar. ${ }^{8} 0$ profissional de saúde, ao investir no aconselhamento em aleitamento materno, compreende melhor os inúmeros significados da amamentação para a mulher, favorecendo a prática da promoção e apoio ao aleitamento a partir da vivência de cada uma. Contudo, apesar das particularidades vividas pelas mulheres na amamentação, o profissional de saúde deve expressar os benefícios da amamentação e promover a sua prática como segurança alimentar. ${ }^{4,8}$

As orientações realizadas pelos profissionais de saúde do BLH favorecem uma escuta sensível, possibilitando à nutriz tomar decisões e fortalecer a autoconfiança, conforme depoimento a seguir:

na orientação e no atendimento, se a sala de coleta estiver vazia, ou na nossa sala de reunião, se estiver vazia, a gente coloca todos, mãe e familiares, e vai buscando ouvir, procurando o motivo da vinda ao $\mathrm{BLH}$, vai conversando, vai usando a técnica de aconselhamento para assistir a mulher na sua demanda real. (PS9) 


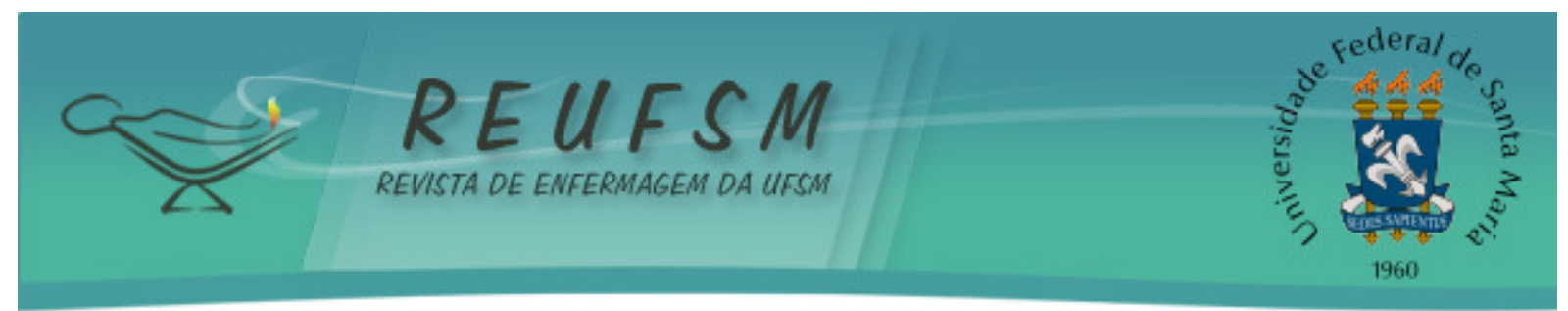

Constata-se que os profissionais de saúde dos BLH utilizam uma linguagem comprometida com a promoção do aleitamento materno, utilizando-a como subsídio para as orientações dos benefícios desta prática já comprovados cientificamente, dando destaque ao processo de assistir a família e a comunidade, ampliando o conhecimento e valorizando o aleitamento materno. Para todos os profissionais envolvidos na orientação às mulheres no período gravídico-puerperal, tem se mostrado um desafio a promoção e apoio ao aleitamento materno, pois melhorar as taxas dos índices desta prática constituem fator de preocupação na garantia da qualidade de vida das crianças em fase de lactância. ${ }^{4}$

As orientações de um profissional de saúde capacitado e especializado na prática do aleitamento materno e nos cuidados com a coleta do leite humano são importantes e essenciais na promoção da segurança alimentar e do bem estar da mulher-nutriz e do bebê. Sendo assim, ele deve orientar com base em evidências científicas no campo do aleitamento materno, esclarecendo à exaustão que esses mitos e tabus não são verdadeiros, que o leite materno não é "fraco", e sim, suficiente em vitaminas e nutrientes que asseguram o crescimento e o desenvolvimento saudável do bebê. A mulhernutriz precisa saber que a amamentação protege as crianças contra infecções dos tratos gastrintestinal e respiratório, sendo maior a proteção quando a criança é amamentada de forma exclusiva por seis meses, e complementada até os dois anos, além de se constituir como a primeira proteção imunológica. 4,9

As orientações para o aleitamento materno passam por esclarecimentos essenciais acerca dos mitos e/ou tabus que prejudicam o aleitamento materno, tais como: o leite materno é fraco, o leite sozinho não alimenta, a mulher produz pouco leite, questões que estão presentes no cotidiano do BLH. Para superar tais mitos e/ou tabus, as orientações devem ser reforçadas porque fazem parte integrante das atribuições do profissional de saúde:

então a gente trabalha, orienta para ver se isso vai quebrando esses tabus de que o leite é fraco. (PS4)

orientação de como tirar o leite quando a mama estiver ingurgitada, orientar que o leite não fica fraco, que não alimenta. (PS25)

As ações de orientação para o aleitamento materno objetivam a educação para a saúde, sendo vivenciadas pelos profissionais de saúde que atuam em BLH sob a forma de rede de atenção em saúde na promoção da amamentação, significando que os integrantes dessa rede ligam-se horizontalmente a todos os demais atores, diretamente ou por meio dos que os cercam. O conjunto resultante é como uma malha de múltiplos fios, que pode crescer indefinidamente para todos os lados, formando a rede de promoção ao aleitamento materno. ${ }^{9}$

Além disso, a educação em saúde para o aleitamento materno preconizada na Rede Amamenta Brasil, aponta para a necessidade da construção de práticas educativas baseadas no trabalho em rede, com a participação de todos os sujeitos desse processo. Para isso, a promoção do leite materno, no foco dos profissionais de saúde do BLH, tangencia as orientações que superam as técnicas tradicionalistas focadas no modelo biologicista e tecnocrata, e tendem a contribuir para uma orientação humanizada com foco na integralidade do cuidado à mulher nutriz. ${ }^{9-10}$

Nesse mesmo sentido de orientação das usuárias do BLH na promoção ao aleitamento materno, os profissionais de saúde atuam ultrapassando as fronteiras dos espaços hospitalares, alcançando os espaços de formação em saúde, como se pode perceber nos recortes de falas a seguir: 


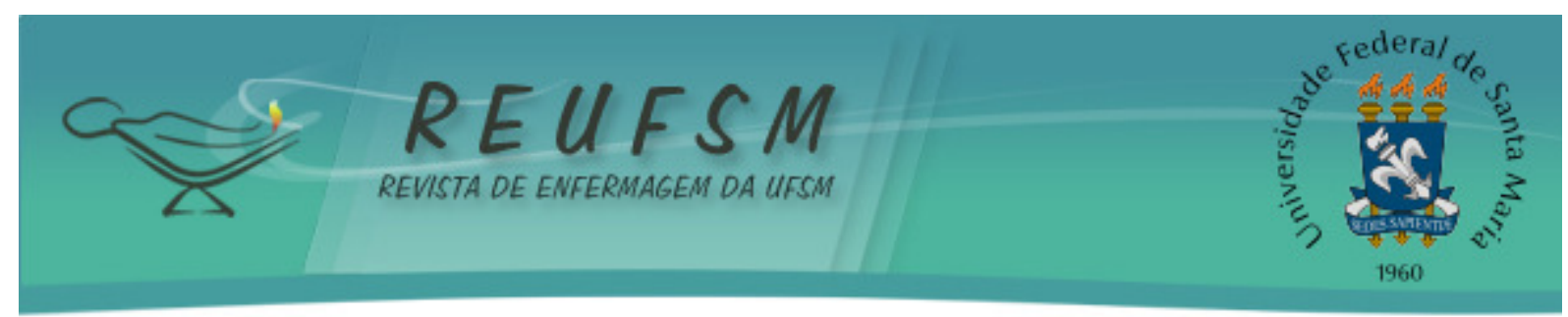

a gente passa a ser multiplicador, tanto para a clientela quanto para os profissionais do setor de saúde, promovendo o aleitamento materno [...] a gente faz a divulgação de campanhas de aleitamento materno também junto aos profissionais de saúde da Universidade, postos de saúde e comunidade. (PS9)

A atuação desses profissionais na prática assistencial da orientação para o aleitamento materno é referida com abrangência de conhecimentos em diversas esferas da educação em saúde como: cuidados com a saúde da mulher e da criança lactente, aconselhamento e manejo clínico do aleitamento materno. Gerando com isso uma escuta delicada, voltada para o atendimento da singularidade de cada situação.

\section{O Banco de Leite Humano como promotor do aleitamento materno no espaço familiar}

A família tem papel importante no processo da amamentação; portanto, o espaço familiar pode ser uma boa estratégia para a promoção e o apoio ao aleitamento materno na medida em que oferecer atenção à mulher no início da amamentação. ${ }^{9}$ Nesse sentido, os profissionais de saúde que atuam nos BLH enfatizam a importância da família em participar dos afazeres cotidianos, parceria considerada indispensável para que a mulhernutriz sinta-se calma, confortável e confiante, assim garantindo a produção do leite para amamentar seu filho.

Os depoimentos a seguir evidenciam a importância de valorizar a participação da família na prática do aleitamento materno:

a gente promove a amamentação [...] com a família, as práticas para o sucesso da amamentação, e se ela está colaborando na amamentação. (PS1)

quando você está orientando a mãe, falando sobre a importância do aleitamento materno, orientá-la na pega e posição correta, orientá-la na amamentação, envolvê-la com a família para dar apoio, ajudar, participar, você está promovendo o aleitamento materno. (PS24)

Cada família constrói sua própria história, sua rotina, com expressões significativas no ato de vivenciar a amamentação, construindo sua cultura na área do aleitamento materno. Os mitos familiares expressos nas histórias contadas cumprem a função de imprimir a marca da família, herança a ser construída na sociedade. Assim, cada família tem uma história de vida que vai se perpetuando ao longo do tempo, constituindo a base dos ensinamentos, crenças e valores repassados aos seus membros. Desse modo, o conhecimento familiar transmitido ao profissional de saúde permite-lhe compreender os mitos e significados do aleitamento materno vivenciados pelos grupos familiares, possibilitando a construção de uma promoção em saúde com foco no apoio à mulher-nutriz, tendo como intuito intervir em prol da prática do aleitamento nesse contexto. ${ }^{9}$

Para esses profissionais de saúde, a promoção do aleitamento materno necessita ir ao encontro dos familiares mais próximos da mulher-nutriz, em especial do seu companheiro, que deve estar inserido no processo gestacional, no parto-nascimento e puerpério, quando a mulher assim o desejar. A prática de promoção do aleitamento materno deve ser fortalecida junto aos familiares, inclusive as avós que trazem consigo conhecimentos e experiências adquiridas durante suas vivências - amamentação de seus 


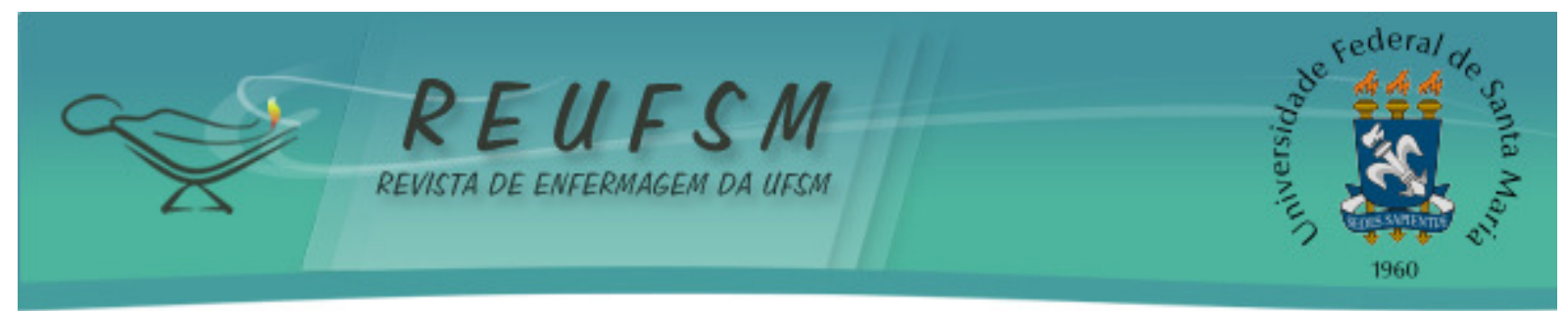

filhos, ou mesmo pela transmissão de valores - mitos, crenças e tabus, de geração em geração. ${ }^{9,11} \mathrm{O}$ conhecimento e a experiência frente à amamentação é fortemente influenciado pelas avós, consideradas importantes figuras de apoio à lactação. ${ }^{12}$ Portanto, a família é entendida como promotora da saúde e do bem estar das mulheres-nutrizes, sendo os profissionais de saúde do BLH facilitadores da atualização e a promoção da amamentação. ${ }^{9,13}$

Geralmente, a rede de apoio da mulher-nutriz traz à tona valores e costumes considerados ultrapassados ou inadequados atualmente, demandando um trabalho de reeducação a fim de evitar a utilização de artefatos, tais como chupetas, para acalmar o bebê. Esse trabalho de reeducação está explícito na seguinte fala:

orientação [...] sogra, pai e mãe chegam aqui com ideias lá do passado, chazinho de erva-doce, chupetinha, e aí a gente vai conversando que essas coisas não se deve fazer, a gente orienta, explica porque não se usa mais. (PS17)

O sucesso da amamentação tem como uma das suas facetas a vinculação da família no processo do aleitar, e as orientações ofertadas pelos profissionais de saúde devem ir ao encontro desta perspectiva de promoção, fortalecendo a rede familiar e possibilitando reconstruir conceitos historicamente constituídos a respeito da prática da amamentação do recém-nascido realizada diretamente no seio da mulher-nutriz. Esse deve ser o principal papel do profissional de saúde em prol da promoção do aleitamento materno. ${ }^{14}$

O apoio familiar constitui uma importante ferramenta para o apoio da prática do aleitamento materno, e nisso o profissional do BLH deve atuar junto aos familiares para apoiar a nutriz quanto à prática da amamentação.

\section{A mídia como ferramenta de promoção do aleitamento materno no espaço do Banco de Leite Humano}

A parceria com os meios de comunicação é uma estratégia rápida e vital para solucionar o problema do baixo estoque de leite humano, além da divulgação de eventos sociais para garantir o apoio ao manejo clínico da amamentação. Uma vez que as campanhas de divulgação sobre os benefícios do aleitamento materno são significativas para o esclarecimento da comunidade com o objetivo de assegurar a redução do desmame precoce. ${ }^{15}$

A promoção do aleitamento materno é focalizada na informação educativa e difundida através dos diversos meios de comunicação (televisão, rádio, jornais, redes sociais), conforme depoimento a seguir:

promoção é o que a gente faz junto à mídia, rádio, TV. Fazemos campanha no Campo de São Bento [...] campanha boca a boca, para divulgar o BLH. Ação Social nas ruas, em praças, isso faz a diferença para o sucesso da amamentação. (PS15)

Os profissionais de saúde dos BLH estão envolvidos com a promoção do aleitamento materno através da mídia, bem como na divulgação da arrecadação de vidros apropriados para uso no BLH a fim de estocar o leite materno cru e pasteurizado para atender as demandas das Unidades Neonatais. ${ }^{15-14}$ Assim, utilizam os meios de comunicação para divulgar a importância da doação do leite e garantir os estoques do BLH. Essa estratégia reafirma a relevância da ação do profissional de saúde do BLH na implementação de 


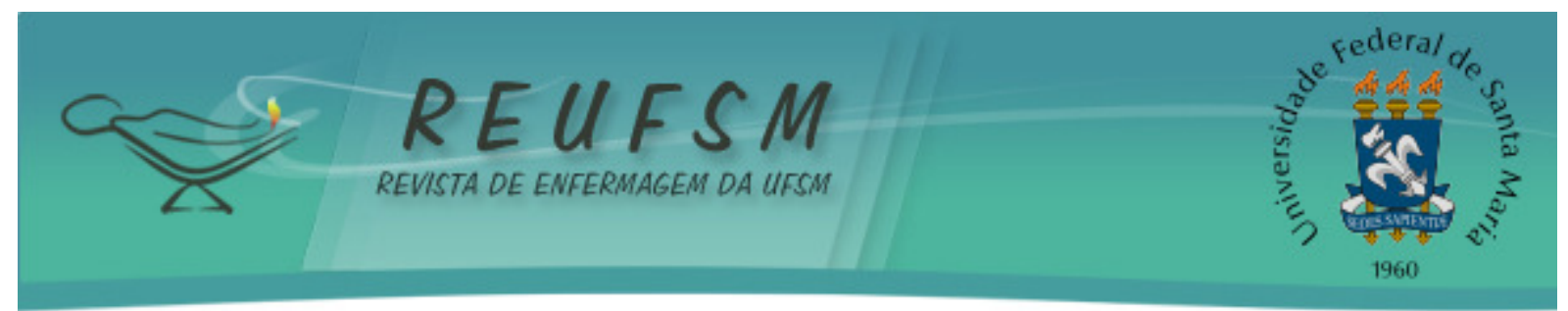

medidas visando a redução da morte neonatal, a partir do fornecimento do leite materno para o recém nascido como segurança alimentar.

Os profissionais de saúde dos BLH utilizam os meios de comunicação para divulgar a importância da doação do leite e garantir os estoques do BLH. A propósito, segue-se o depoimento de um participante:

a gente faz diversos tipos de divulgação para conscientizar as mães que estão em casa com leite excedente e não sabem o que fazer, estimulamos a estar doando seu leite bem como apoiando para a amamentação [...] faz divulgação em rádio, TV, todo tipo de mídia [...] outdoor, para a cidade toda estar se conscientizando que banco de leite existe, leite é vida e a gente precisa dele. (PS7)

A sensibilização das mulheres-nutrizes é essencial para a doação do leite humano e para a manutenção do aleitamento materno; portanto, divulgar a importância da doação de leite humano e a sua distribuição aos recém-nascidos prematuros e a outros lactantes temporariamente impossibilitados de serem amamentados, é uma estratégia de saúde. ${ }^{15}$ As doadoras são grandes promotoras da divulgação da doação do leite humano, pois elas identificam a doação como um ato de amor e responsabilidade social, fortalecendo uma rede social que garante a troca de experiências entre mulheres sobre 0 ato de amamentar. ${ }^{16}$

Os profissionais de saúde do BLH percebem as vantagens das ações de promoção do aleitamento materno nos espaços da mídia para a ampliação da doação de leite humano, bem como para o atendimento dos transtornos da lactação. Assim, a ampliação da arrecadação de leite humano é fundamental para atender as demandas das Unidades Neonatais, como mencionado:

a gente divulga a respeito do Banco de Leite para outros lugares, aí as pessoas ligam, a gente passa a informação por telefone e pede para vir até o Banco para o primeiro encontro. (PS4)

se fizermos campanha vem mais, se não, vem menos mães doarem seus leites. Então, a gente deixa de ter matéria-prima. (PS9)

Outra estratégia utilizada pelos profissionais do BLH para utilização da mídia é a divulgação de datas comemorativas como o Dia Internacional de Doação de Leite Humano, a Semana Mundial do Aleitamento Materno, dentre outras, nas quais se desenvolvem várias atividades entre elas: palestras, passeatas e entrega de prêmios para as doadoras e parceiros institucionais. Assim relataram dois entrevistados em seus depoimentos:

nós fazemos uma tenda do aleitamento materno em outras maternidades e praças, paramos as pessoas na rua! Nós damos panfletos, falamos da proteção para o bebê com o leite humano em especial nos dias das mães. (PS7)

a gente faz um trabalho nas datas comemorativas, promovemos pela mídia, dando importância para a doação e amamentação. (PS19)

A mídia é, sem dúvida, uma ferramenta extraordinária no campo da saúde, e no aleitamento materno possibilita maior abrangência na sociedade, quando utilizada adequadamente. Nessa linha de raciocínio, os profissionais de saúde dos BLH utilizam-na 


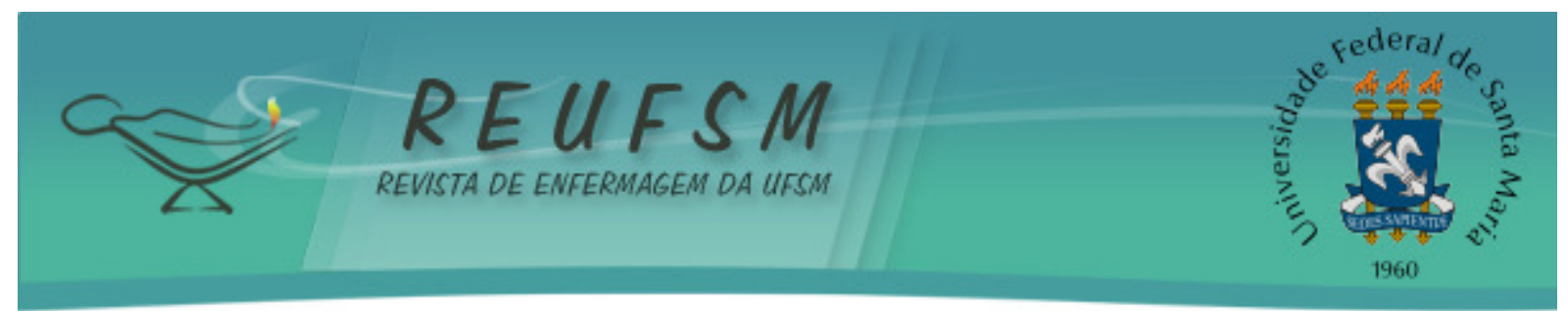

como ferramenta de trabalho para a promoção do aleitamento materno como prática social. ${ }^{16}$ Em uníssono, o fazer desses profissionais de saúde que atuam em BLH torna-se relevante prática comum, dado observado no enfrentamento da carência de leite humano para atender a demanda.

\section{CONCLUSÃO}

A promoção do aleitamento materno na prática assistencial dos profissionais de saúde de BLH do Estado do Rio de Janeiro demarca abordagens com técnicas básicas de aconselhamento e estratégias criativas com foco direcionado para segmentos específicos de público-alvo, reconhecendo o valor do papel da família, da comunidade e da eficácia da mídia como rede de apoio para o sucesso do aleitamento materno. Percebem que a responsabilidade da transformação da prática alimentar da criança transcende seus fazeres, havendo necessidade de maiores investimentos na formação acadêmica na prática do aleitamento materno pelos profissionais de saúde e comprometimento permanente de cada um na educação de base.

Estes profissionais que atuam nos BLH demonstram ter um papel social amplo no campo da redução da morte neonatal, em especial como promotor do aleitamento materno com foco nos direitos sociais, direitos das mulheres e das crianças e na segurança alimentar, o que torna o espaço do BLH um local de debate que ultrapassa a ótica biológica, articulando a questão social como marca de direitos humanos e de direito a uma vida saudável.

O estudo não houve limitação. A prática na promoção do aleitamento materno realizada pelos profissionais de saúde do BLH mostrou a realidade vivida em cada Unidade estudada, como se apropriam e enfrentam as precariedades das condições de trabalho, além dos esforços e a certeza que suas funções podem mudar a cultura alimentar da criança.

\section{REFERÊNCIAS}

1. Brasil. Agência Nacional de Vigilância Sanitária (Anvisa). Banco de leite humano: funcionamento, prevenção e controle de riscos. Brasília: Anvisa; 2008 [acesso em 2014 fev 12]. Disponível em: http://www.redeblh.fiocruz.br/media/blhanv2008.pdf. (Série Tecnologia em Serviços de Saúde).

2. Moreira MEL at all. Práticas de atenção hospitalar ao recém-nascido saudável no Brasil. Cad Saúde Pública. 2014 [acesso em 2014 fev 12];30 Supl 1: Disponível em: http://dx.doi.org/10.1590/0102-311X00145213.

3. Brasil. Ministério da Saúde. Secretaria de Atenção à Saúde Departamento de Ações Programáticas e Estratégicas. Pesquisa de prevalência de aleitamento materno em municípios brasileiros: situação do aleitamento materno em 227 municípios brasileiros. Brasília (DF); 2010 [acesso em 2014 fev 12]. Disponível em: http://www.redeblh.fiocruz.br/media/pamuni.pdf.

4. Fonseca-Machado MO, Hass VJ, Stefanello J, Nakano AM, Gomes-Sponholz F. Aleitamento materno: conhecimento e prática. Rev Esc Enferm USP. 2012;46(4):809-15.

5. World Health Organization (WHO). Global strategy for infant and young child feeding. In: 54th World Health Assembly; 2001 Apr 9; Geneva: WHO; 2001.

6. Minayo MCS. O desafio do conhecimento: pesquisa qualitativa em saúde. $12^{\mathrm{a}}$ ed. São Paulo (SP): Hucitec; 2010. 


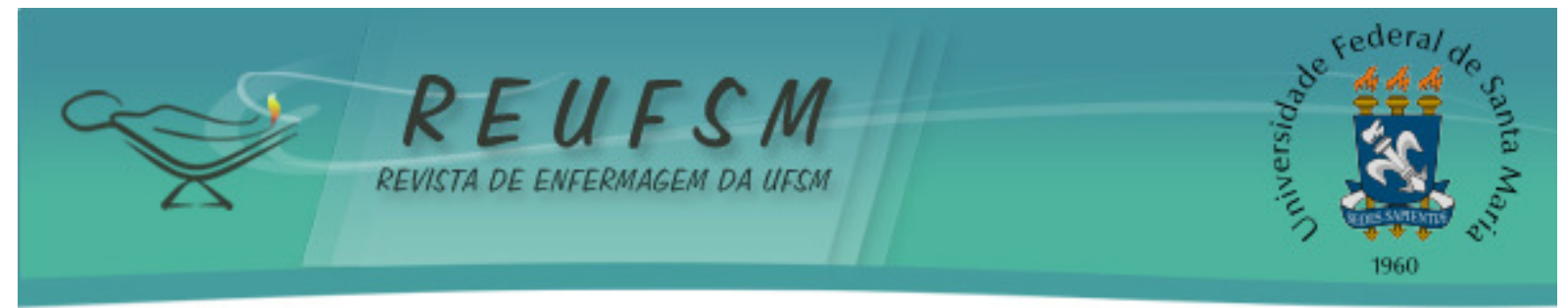

7. Bardin L. Análise de conteúdo. $4^{\mathrm{a}}$ ed. Lisboa: Edições 70; 2009.

8. Brandão EC, Silva GRF, Gouveia M TO, Soares LS. Caracterização da comunicação no aconselhamento em amamentação. Rev Eletrônica Enferm [Internet]. 2012 abr/jun [acesso em 2014 fev 12];14(2):355-65. Disponivel em: http://dx.doi.org/10.5216/ree.v14i2.12748.

9. Marques ES, Cotta RMM, Magalhães KA, Sant'Ana LFR, Gomes AP, Siqueira-Batista R. A influência da rede social da nutriz no aleitamento materno: o papel estratégico dos familiares e dos profissionais de saúde. Ciênc \& Saúde Coletiva. 2010; 15 Supl 1:1391-400.

10. Passanha A, Benício MHD, Venâncio SI, Reis MCG. Implantação da Rede Amamenta Brasil e prevalência de aleitamento materno exclusivo. Rev Saúde Pública [Internet]. 2013 [acesso em 2014 fev 12];47(6):1141-8. Disponível: http://dx.doi.org/10.1590/S00348910.2013047004807.

11. Alves VH, Rodrigues DP, Gregório VRP, Branco MBLR, Souza RMP, Alves CMCSH. Reflexões sobre o valor da amamentação como prática de Saúde: uma contribuição da enfermagem. Texto \& Contexto Enferm [Internet]. 2014 acesso em $2014 \mathrm{fev}$ 12];23(1):20310. site: http://www.scielo.br/pdf/tce/v23n1/pt_0104-0707-tce-23-01-00203.pdf.

12. Moreira MA, Nascimento ER, Paiva MS. Representações sociais de mulheres de três gerações sobre práticas de amamentação. Texto \& Contexto Enferm [Internet]. 2013 abr./jun [acesso em 2014 fev 12];22(2):432-41. Disponivel em: http://dx.doi.org/10.1590/S0104-07072013000200020.

13. Paula AO, Sartori AL, Martins CA. Aleitamento materno: orientações, conhecimento e participação do pai nesse processo. Rev Eletrônica Enferm [Internet]. 2010 [acesso em 2014 fev 12];12(3):464-70. Disponível em: http://dx.doi.org/10.5216/ree.v12i3.6929

14. Baptista SS, Alves VH, Souza RMP, Rodrigues DP, Cruz AFN, Branco MBLR. Manejo clínico da amamentação: atuação do enfermeiro na Unidade de Terapia Intensiva Neonatal. Rev Enferm UFSM [Internet]. 2015 jan/mar [acesso em 2014 maio 11];5(1):23-31. Disponível em:

2.2.2/index.php/reufsm/article/view/14687.

15. Pinto MCLM, Campelo TC, Ram,os CV, Lima MER, Pereira TG. Alegações maternas para doação de leite humano ao banco de leite em Teresina-Piauí. Rev Interdisciplinar NOVAFAPI, Teresina [Internet]. 2012 [acesso em $2014 \mathrm{fev}$ 12];5(2):15-20. Disponível em: http://www.novafapi.com.br/sistemas/revistainterdisciplinar/v5n2/pesquisa/p2_v5n2.pdf

16. Neves LS, Mattar MJG, Sá MVM, Galisa MS. Doação de leite humano: dificuldades e fatores limitantes. Mundo Saúde. 2011;35(2):156-61.

Data de recebimento: $22 / 12 / 2014$

Data de aceite: $20 / 07 / 2015$

Contato do autor responsável: Diego Pereira Rodrigues

Endereço postal: Rua Desembargador Leopoldo Muylaert, 307, Piratininga - Niterói (RJ) CEP: 24350-450.

E-mail: diego.periera.rodrigues@gmail.com 